\title{
Assessing Emotional Intelligence Factors and Commitment towards Organizational Change
}

\author{
Nini Hartini Asnawi, Noorlaila Hj Yunus, and Norfadzilah Abd Razak.
}

\begin{abstract}
Emotional intelligence becomes important competencies and ability needed by most of the employees to confront with the workplace environment. While there are changes in the workplace, most of the employees anxious to face with the changes. Change perceived as threatening for employee's emotions and reflects their commitment to change. Hence this paper formulates a framework of comprehensive model emotional intelligence to further understanding commitment to change in the workplace. In essence, this paper framework shows how the individual practicing emotional intelligence in gaining commitment to successful implementation of change. This framework addresses the consequences for the employees to give high commitment, and participation in successful implementation of changes. Finally, a discussion on the implications for future theory development is presented.
\end{abstract}

Index Terms-Emotional intelligence, employees commitment and organizational change.

\section{INTRODUCTION}

The twenty-first century is generally regarded to be a century of globalization, adaptation of technology advancement, political and social changes and highly competitive. There are many elements that force the organization to change. Change in an organization is inevitable. It is difficult to be avoided and perceived as challenges to the organization. Recently one of the focal concerns has been the competency in managing change. The change affects the organizational workflow, organization cultures, leaderships and other similar issues [1]. Change challenges how things have always been done and affects the individual emotions which reflect individual commitment to change. Each individual in the organizations has their own belief and values. When change occurs, existing belief, values and behavior were challenged too. However, emotional intelligence has been found as the abilities for the individual should have in order to respond and managing change [2]. Emotional intelligence plays an integrated part in helping organizations [3]. While individual fail to manage their emotions, indirectly people are resisting accepting change. People resist changing and reflecting to low self motivation to perform their work. However there is little attention on gaining commitment among the people. Most of the students had done resist to change. But there are gaps in

Manuscript received June 20, 2013; revised August 22, 2013. This work was collaboration with Universiti Teknologi Mara, (UiTM) and Research Management Institution (RMI).

The authors are with the Universiti Teknologi MARA, Faculty Business Management, Campus Puncak Alam, 42300 Puncak Alam (e-mail: niniha3000@puncakalam.uitm.edu.my, norfadzilah266488@yahoo.com, nlaila814@salam.uitm.edu.my). gaining commitment from employees towards the change [4]. Therefore, this study aims to understand the individual commitment through adapting emotional intelligence in workplaces. In the context of higher education institutions, this study is a bit scarce. Recently, Malaysia higher education in university level plans for several transformational changes in order to improve the quality of the education. In this context, administrative level perceived as the main roles to support and implement all the strategies to change Significantly, their contribution will ensure the successful implementation of change and achieve the sustainability in higher education.

\section{Problem Statement}

Change is often perceived as an opportunity or a threat, excitement and happiness or anger and fear, positive or negative intentions. According to [5] when change is viewed as an opportunity, positive emotions would make the individual more amenable and likely motivate to act positively. This is because a person's cognitions, emotions and action are intimately interlinked [6]. In higher education perspectives there seek change adaptability to improve their competitive position [7] and this has led to growing interest in the benefits of emotional intelligence and requires employee involvement such as participation in decision-making [8]. Employee's participation in decision making defined as the act of working together and collaborative makes the decision to achieve organizational goals Employees who are able to influence decisions affecting them are more likely to value the outcomes such as motivational effects, job satisfaction and individual commitment [9]. Previous study determines there are critical process of change includes of receptivity, and mobilization [10]. Receptivity represents an individual willing to consider change and recognize the purpose of the change. In other words is a process shapes by continuous sense making and a sense of giving activities which conducted among the members of the organization. In another point of view [6] claims that mobilization involves collaborative efforts and the capacity to implement change and view as concrete action to be taken to adapt the change. It requires the commitment and effort to change.

However, there were several factors leads to the failures of the changes. Some of the people afraid of losing something value, misunderstanding the change and its implications believe that change does not make any sense or have a low tolerance for change [11]. Additionally, the other study support that there were seventy percent of the change program fails because of lack strategy and vision, lack of 
communication and trust, lack of top management commitment, lack of resources, lack of change management skills, and resistance to change [12]. As mention above, people participate in making the decision will reduce all failure factors and leads to the succession of implementing change. Somehow, when employees have limitation to involve in making decision, it leads to the ambiguity roles, stress, low self efficacy and low performance. This happens because not all of the employees can accept the change. There is little attention has been paid to the definition and measurement of commitment within a change context, and there is virtually no empirical evidence to substantiate the claims made about its effects. Moreover, there is insufficient the quantity of literature which examined the relationship between emotional intelligence and commitment to change.

The gap in this study tries to fill looked at individual consideration in managing the emotions towards commitment to change. This is important because according to [13] organizations that achieve high levels of commitment among employees were reaping the benefits. Instead of that, emotionally intelligent ability able to cope with any issue regards of the change. Organizations confronting change need to recognize the value of developing employees' emotional intelligence to allow them to participate more effectively in decision processes. Moreover, through participation among the employees, empowers emotionally intelligent among employees to contribute to commit to change.

\section{LITERATURE REVIEW}

\section{A. Theory of Emotional Intelligence at Workplaces}

In the recent year, there have been considerable and growing interests in the concepts of emotional intelligence (EI) at workplaces. The emerging literature on EI contains a variety of definition, concepts and model [14], [15], [16] and [17]. According to [14] defined an emotional competence as learned capabilities based on emotional intelligence by demonstrating the competencies of self awareness, self management, social awareness, and social skills at workplace environment. In useful definition of EI which is understand own feeling, being able to motivate own self to get jobs done, be creative and perform at work place, sensing what others are feeling and handling relationship effectively. There are five major dimensions describe the theory of emotional intelligence. It includes social awareness, self regulation, self motivation, self awareness and social skills. Different with Mayer and Salovey's model of emotional intelligence as including four dimensions consist of self emotions appraisal others emotions appraisal, regulation of emotions and use of emotions.

Self emotions appraisal refers to an individual's ability to understand in deep emotions and able to express the emotions naturally. It is described who were more precise on self emotionally more promptly perceived and take action to own emotions and better state emotions to others. Other emotions appraisal is defined in the situation of appraising and respects of others emotions. It means an individual able to perceive and recognize the emotions of those people around them. Use of emotion explained an ability of individuals to make utilize of own emotions by direct them towards positive activities and personal performance. A person who is highly capable in this dimension maintains positive emotions most of the time and is capable to promote him or her to do better constantly. In other terms it is encouraging the individual to inspire themselves to be better. Regulation of emotion relates to the ability of individuals to control own emotions, which enable quick recovery from psychological distress A person with high ability in this area would be able to return hastily to a normal psychological state after experiencing distress. People who rate highly in this ability would be less likely to lose their anger and control their own emotions.

By contrast emotional intelligence as non cognitive capabilities, competencies and skill that influence one's ability to succeed in coping with the work environmental demand and pressures. Meanwhile, a theory from [18] defines emotional intelligence as the skill of an individual to scrutinize one's own and others' emotions; to distinguish among the positive and negative effects of emotion; and to use emotion in sequence to guide one's thinking and actions.

However in this study conceptualized the theory which is directly related to verify the competency and ability of individual in adapting the changes in workplaces. According to [19] in his study explained the theory by Reuven Baron essentially consists of certain emotions, social competencies, skills and facilitators. In different point of view, [20] clarifies that the Bar On theory are designed as mixed ability as a mixture of ability and personality necessary at the workplace. There are five elements includes of interpersonal, intrapersonal, adaptability, stress management and general mood. Most people with this ability express emotions in naturally sense and acknowledge better of own emotions [21]. The other studied considerate of own emotions relates to understand the emotions of other people. People who are high in this ability were very sensitive to the feelings of others and predict the responses by others It means concern to the others feelings and aware of the individual act or respond based on their emotions.

\section{B. The Three-Component Model of Organizational Commitment}

It is extensively established that employee commitment to organizations can take unusual forms, and that acknowledge these differences which enable researchers to make more specific predictions about the impact of commitment on behavior [22]. There were describes a committed employee is one who stays with the organization through substantial and slight, attends work frequently, puts in a full day and more protects company resources, and share company goals. In the past, [23] defines commitment as a psychological state or way of thinking influences employees retain attachment in an organization. In this study the commitment was studied in the context of change. According to [24] described commitment to change as the glue that provides the vital acquaintance between people and change goals. Meanwhile [25] defined commitment as a fundamental component in their model of effective modernization implementation in the workplace. Similarly, [26] included commitment as a key inconsistent in their theoretical model of system readiness for change. A 
prior study supported commitment to change is one of the most significant factors to support change initiatives [27].

In related studies of commitment to change, [28] initiate that each component of commitment related confidently to compliance with the requirements for change. It clarifies positively to an employee's readiness go beyond the least amount requirements to make change of their work. There were three dimensions of commitment to change which adapted from the [29] comprises of affective, continuance and normative commitment. In other words, the commitment to change explain as individuals who were feeling bound to support a change because they want to change, have to change, or must to change. They determine there are three major determinants to measure the commitment by dissimilar mind-sets and argued that employees can experience varying combinations of all three mind-sets simultaneously.

In the main, the research shows that those employee's with a strong affective commitment will remain with an organization because they will want to stay in organization [30] remain and showed their commitment thought as voluntary to stay. Furthermore employees were seen as having a sense of belonging and credentials involve in the organization's activities, willingness to follow the organization's goals and retain within the organization. In relation to the emotional intelligence, other studied defined affective commitment as the emotional attachment, identification, and involvement that an employee has with its organization and goals. Another study founds employees' emotional tie to the organization had considered of dedication and loyalty [31] towards the organization. Instead of that, affective commitment is the commitment based on the emotional ties a worker develops with an organization [32].

Normative commitment views in a different concept. Those who remain out of a sense of responsibility refer to normative commitment. Employees do likewise only if employees see it as a part of the duty, or as a means of reciprocation for benefits received. Normative commitment reflects a feeling of obligation to continue employment. Employees with a high level of normative commitment feel that they ought to remain with the organization. Other studied by [33], normative commitment describes a person believes that they have to the organization or their feeling of obligation to their workplace.

In contrast, employees who remain first and foremost to avoid costs were referring to continuance commitment. Continuance commitment claim of attentiveness of the costs associated with leaving the organization. Employees whose primary link to the organization is based on continued commitment remain because they must to do so. To those with a strong continuing commitment remain because they have to preserve in the organization. In further explaining that employees who share continuance commitment with employer often make it very hard for an employee to leave the organization. It also mentioned continuance commitment can be thought as needed to stay. A prior studied by [34] on reasons employees hesitant to leave the organization under continuance commitment because of the deal that the employee has with nontransferable investments. Nontransferable investments include things such as retirement, relationships with other employees, or things that are special to the organization. In addition, continuance commitment also includes factors such as time of employment or reimbursement that the employee may receive that are exclusive to the organization.

\section{Relationship Emotional Intelligence and Commitment to Change.}

Changes lead to the new innovation and creativeness which emotionally for organizational staff to embrace the change [35]. It is necessary for both the organization and employees to realize the changes occurred and meet their need [36]. Much past research has supported commitment to change is one of the most important factors to support change initiatives [37]. As [38] highlighted a committed employee is the one who stays with the organization through thick and thin, attends work regularly, puts in a full day and protects a company's assets, share company goals, and so on. Because of that, the sign of change gives employees an emotional charge and has taken seriously in managing the change. In another major study, [39] found the relationship between emotional intelligence and commitment to change has been widely investigated. It would help employees to identify own abilities in social and managing the emotions at workplace. This view was supported by [6], who pointed out there was a positive relationship between emotional intelligence and commitment to change which contributed to the job performance. Furthermore, [10] mentioned employees who have a good level of emotional intelligence were committed to the changes. Moreover, there is a positive and statistically significant relationship between the emotional intelligence and commitment to change [11].

In essence, [18] asserted that organizational change can be successful if employees are committed to its work. They claimed that commitment is best when it is based upon a belief in the value of the initiative and employees wanting to see it succeed. The concept of organizational commitment emerged from studies exploring employees- organization linkages. Whereas, [19] provide empirical support that organizational commitment is a multidimensional concept that provides a complete insight into the link between employees and work related performance. There were believed that employees can experience all three forms of commitment to varying degrees. They claimed that given these conceptual differences, the psychological states reflecting the three components of organizational will develop as the function of quite different antecedents and have different implications for work behavior. Literatures point out that organizational commitment and involvement is one of the important elements that have an impact on organizational change. For example employees high in affective commitment, for example, demonstrate emotional affection and identification with their involvement in the organization. This would explain why these employees are less likely to engage in leaving behavior and are more willing to accept change.[40] argued that a highly committed employee is more willing to agree to organizational change if it is perceived to be beneficial. Similarly, [41] suggests that organizational commitment will outcome in a willingness to accept organizational change. In sum, a greater degree of organizational commitment should lead to successful 
organizational readiness for a change process. Therefore, having much said about work related attitude and their effect on organizational change, this study suggests that a positive relationship exists commitment and emotional intelligence on organizational readiness for change.

\section{CONCEPTUAL FRAMEWORK}

Consequently, in this study the independent variable (determinants of emotional intelligence factors) applies to the dependent variable (commitment to change). It is to understand the relationship between emotional intelligence and individual commitment to change. Figure 1 illustrates the proposed conceptual framework of emotional intelligence factors influences individual commitment to change. In this study, the determinants of emotional intelligence factors were adapted from [11] actually adapted the essential theory from [19]. This theory is most related to determine the competencies of individual employees in the workplace rather that personality needed. It related to identify the competencies needed in managing and understand own and others emotions in workplaces. Meanwhile, the elements of commitment to change was revised from [29] and adapted in this concept study. Recently, this practice had widely used to determine the employee commitment at workplaces. There are two things may result from this integration.

First the employees in deal with the changes by understand and able to manage their emotions during changes occurs. Employees engage with the workplace environment and give the highest commitment to support and implement the changes. Second, the most important part, individually and organization gain mutual agreement to the changes and work collaborative to ensure the implementation of change to benefit both parties. This will retain all the employees to remain in the organization and participate in making decisions together.

(1) Proposed Conceptual Framework

\begin{tabular}{|c|c|}
\hline Emotional Intelligence & Commitment to \\
\hline Factors & Change \\
\hline Self Emotion Appraisal & Affective \\
\hline Other Emotion & Commitment \\
\hline Appraisal & Normative \\
\hline Regulate Others & Commitment \\
\hline Emotions & Continuance \\
\hline Use of Emotions & Commitment \\
\hline
\end{tabular}

Fig. 1. The influences of emotional intelligence factors and individual commitment towards change.

Based on the framework above, several hypotheses will be tested at the following:

H1: There is a significant relationship exists between the emotional intelligence and commitment to change.

H1a: Self emotions appraisal significantly influences individual commitment to cope with workplace changes. $\mathrm{H} 1 \mathrm{~b}$ : Other emotions appraisal significantly influences individual commitment to cope with workplace changes. H1c: Regulate others emotions significantly influence individual commitment to cope with workplace changes. H1d: Use of emotions significantly influences individual commitment to cope with workplace changes.

\section{DISCUSSION AND RECOMMENDATION}

Emotional intelligence is the competency, ability and skill that needed by most of the individual to commit to their work. According to [42] who generally found that the ability to appraise and understand one own emotion does not significantly influence the individual's overall commitment to his or her organization. In another study also supported that, an individual understands the others emotion during change, a better communication needed to ensure the success of change. An individual who has this ability assume will be much more sensitive of others feeling and understand the reasons why people around them act and behave as well [43]. Meanwhile [44] claimed that when individuals are able to use their emotion inappropriate manner, they will be more committed towards the change and consequently encourage and motivate them to commit to their roles and duties. Therefore, the role of emotional intelligence plays in moderating stress and increasing commitment to change [45]-[48]. A person with high ability to regulate of emotions would be able to return quickly to a normal psychological state after rejoicing or experiencing distress. People who rate highly in this ability would be less likely to lose their temper. Further to the study, the effectiveness of practicing emotional intelligence is a major concern of the individual and the organization in gaining commitment to implement change. Therefore the recommendations of this study have looked into two perspectives of employees and the organization.

The organization able to strategies and train the employees able to use emotional intelligence in workplaces. The practices of the emotional intelligence will determine commitment and participation among employees to retain the productivity, and quality in the organization. First, the management should consider selecting staff with high EI abilities and developing the EI skills and abilities especially Self Emotional Appraisal (SEA) and Others' Emotional

Appraisal (OEA) so that the human capital is ready to pursue particular strategies in their work. Second, given that EI abilities can be developed training in specific areas of EI would guarantee that the employees could perform their work as expected by the management [49]. And lastly, employee performance appraisal should also consider the employees' EI abilities so that those who successfully apply these abilities on the job are appropriately rewarded. The employees who practices emotional intelligence will reflect to actively participate in an organization and to improve their knowledge, skills and abilities in performing their jobs. Employees perceived the changes actually benefit them as long they able to manage their emotions during changes.

\section{CONCLUSION}

As a conclusion to this concept study, emotional intelligence becomes increasingly valued in the workplace in 
the future emotional intelligence. It is a part of the competencies which individual should have in managing the change. This is suitable to the perception for most of the people which believe the ability in managing own and others emotions have a lot of positive impact of their job behavior and the way of employees' thinking. Through this study also has figured out that by having a better understanding of emotional intelligence at the workplace, there were highly tendency of the employees can adapt to any kind of change situation and consequences. An individual who has the emotional intelligence assume is the great employees in the organization. The ability to managing own and others emotions make an individual to positive thinking and action to react to the changes. Moreover, employees encourage giving high commitment to the change process. It influences the employees' job behavior to enhance the level of commitment towards the change. Generally changes bring a lot of challenges. It affects the emotions and react the behavior based on the emotions towards the changes. However in adapting the emotional intelligence in the workplace will make all people within the organization openness to change and prepare themselves towards the change. As a result, the changes implement are successful in the end.

\section{ACKNOWLEDGMENT}

This research was supported by the Research Management Institute (RMI) of Universiti Teknologi MARA, under the grant Research Incentive Faculty (RIF).

\section{REFERENCES}

[1] C. Erikkson, "The effect of change programs on employees' emotions," Personal Review, vol. 33, no. 1, pp. 110-126, 2004.

[2] D. Goleman and C. Cherniss. (1998). "Bringing Emotional Intelligence to Workplace. The Consortium For Research On Emotional Intelligence In Organizations Retrieved. [Online]. Available: http:// www.eiconsortium.org.

[3] R. D'Intino, M. Goldsby, J. Houghton, and C. Neck, "Self-Leadership: A process for entrepreneurial success," Journal of Leadership \& Organizational Studies, vol. 13, no. 4, pp. 105-120, 2007.

[4] G. Stewart, "The relationship of emotional intelligence to job satisfaction and organization commitment (Doctoral dissertation, Regent University, United States -Virginia, 2008)," Dissertations \& Theses: Full Text database, 2008.

[5] S. Lazarus, "From psychological stress to emotions: a history of changing outlooks," Annual Review Psychology, vol. 44, no.1, pp. 1-21, 1993.

[6] C. Erikkson, "The effect of change programs on employees' emotions," Personal Review, vol. 33, no. 1, pp. 110-126, 2004.

[7] V. U. Druskat and S. B. Wolff, "Building the Emotional Intelligence of Groups," Harvard Business Review, vol. 79, no. 3, pp. 80-90, 2001.

[8] B. S. Ladd and C. C. A. Chan, "Emotional intelligence and participation in decision-making: strategies for promoting organizational learning and change," Strategic Change, vol. 13, no. 2, pp. $95-105,2004$.

[9] L. A. Witt, M. C. Andrews, and K. M. Kacmar, "The role of participation in decision making in the organizational politics-job satisfaction relationship," Human Relations, 2000, vol. 53 no. 3, pp. 341-358.

[10] Q. Huy, "Emotional capability, emotional intelligence and radical change," Academy of Management Review, 1999, vol. 24, no. 2, pp. $325-345$.

[11] C. Wong and K. Law, "The effects of leader and follower emotional intelligence on performance and attitude: an exploratory study," Leadership Quarterly, vol. 13, no. 3, pp. 243-274, 2002.

[12] M. Beer and N. Nohria, "Cracking the code of change," Harvard Business Review, May/June, 2000, pp. 133-41.
[13] J. Meyer, "Commitment in a changing world of work," in H. Klein, T. Becker, \& J. Meyer (Eds.), Commitment in organizations: Accumulated wisdom and new directions, New York: Taylor \& Francis Group, pp. 37-68, 2009.

[14] P. Salovey and J. Mayer, "Emotional intelligence," Imagination, Cognition and Personality, vol. 9, no. 3, pp. 185-211, 1990.

[15] D. Goleman, Emotional intelligence: why it can matter more than IQ, London: Bloomsbury, 1995.

[16] R. Cooper and A. Sawaf, Executive EQ: Emotional Intelligence in Leadership and Organisations, New York: Grosset/Putnam, 1997

[17] R. B. On, The Emotional Intelligence Inventory (EQ-I): Technical manual, Toronto: Multi-Health Systems, 1997.

[18] D. Goleman and C. Cherniss. (1998a). Bringing Emotional Intelligence to Workplace. A Technical Report Issued By The Consortium For Research On Emotional Intelligence In Organizations [Online]. Available: http: // www.eiconsortium.org.

[19] P. Salovey and J. Mayer, What is emotional intelligence?, in P. Salovey and D. J. Sluyter, (Eds), Emotional Development and Emotional Intelligence: Educational Implications, Basic Books, New York, NY, 1997.

[20] B. Mallery. (2010). Emotional intelligence. [Online]. Available: http://positivepsychology.org.uk/.

[21] J. Gross, ":The emerging field of emotion regulation: an integrated review," Review of General Psychology, 1998b, vol. 2, no. 3, pp. 271-299.

[22] K. Law, C. Wong, and L. Song, "The construct and criterion validity of emotional intelligence and its potential utility for management studies," Journal of Applied Psychology, vol. 89, pp. 483-496, 2004

[23] J. Meyer and N. Allen, Commitment in the Workplace: Theory, Research, and Application, Thousand Oaks, CA: Sage Publications, 1997.

[24] J. Meyer and N. Allen, A Three Component Conceptualization of Organizational Commitment, Human Resource Management Review, 1991, vol. 1, pp. 61- 98.

[25] D. Conner, Managing at the speed of change: How resilient managers succeed and prosper where others fail, New York: Villard Books, 1992.

[26] K. Klein and J. Sorra, The challenge of innovation implementation Academy of Management Review, 1996, vol. 21, pp. 1055-1080.

[27] A. Armenakis, S. Harris, and H. Feild, Paradigms in organizational change: Change agent and change target perspectives, in R. Golembiewski (Ed.), Handbook of organizational behavior, 1999, pp. 631-658, New York: Marcel Dekker.

[28] L. Coetsee, From resistance to commitment, Public Administration Quarterly, 1999, vol. 23, pp. 204-222.

[29] L. Herscovitch and J. Meyer, "Commitment to Organizational Change: Extension of a Three-Component Model," Journal of Applied Psychology, vol. 87, no. 3, pp. 474-487, 2002.

[30] J. Meyer, N. Allen, and C. Smith, "Commitment to organizations and occupations: Extension and test of a three-component conceptualization," Journal of Applied Psychology, vol. 78, pp. 538-551, 1993.

[31] L. Rhoades, R. Eisenberger, and S. Armeli, "Affective Commitment to the Organization: The Contribution of Perceived Organization Support," Journal of Applied Psychology, vol. 86, no. 5, pp. 825-836, 2001.

[32] S. Jaros, "Meyer and Allen model of organizational commitment. Measurement issues." The Ifai Journal of Organizational Behavior, vol. 5, no. 4, pp. 7-25. 2007.

[33] D. Bolon, Beyond job satisfaction: A multidimensional investigation of the relationship between organizational commitment and organizational citizenship behaviors, Unpublished doctoral dissertation, Virginia Polytechnic Institute, 1993.

[34] A. E. Reichers, "A review and re-conceptualization of organizational commitment," Academy of Management Review, vol. 10, pp. 465-476, 1985 .

[35] J. Meyer, T. Becker, and C. Vandenberghe, "Employee commitment and motivation: A conceptual analysis and integrative model," Journal of Applied Psychology, vol. 89, no. 6, pp. 991-1007, 2004.

[36] M. Zeidner, G. Matthews, and R. Roberts, What we know about emotional intelligence: How it affects learning, work, relationships, and our mental health, Cambridge, MA: MIT Press, 2009.

[37] P. Pritchett, Culture Shift, Pritchett, Rummler-Brache, Dallas, TX, 2004.

[38] A. Cork, "A model for successful change management," Nursing Standard, vol. 19, no. 25, pp. 40-42, 2005.

[39] A. Armenakis, S. Harris, and H. Feild, "Paradigms in organizational change: Change agent and change target perspectives," in Handbook of organizational behavior, R. Golembiewski (Ed.), 1999, pp. 631-658. New York: Marcel Dekker. 
[40] C. M Lau and R. W. Woodman, "Understanding Organizational Change: A Schmematic Perspectives," Academy of Management Journa, vol. 38, no. 2, pp. 537-554, 1995

[41] D. Guest, "Human Resources Management and Industrial Relations, Journal of Management Studied,vol. 24 , no. 5, pp. 503-521, 1997.

[42] S. Bedwell, Emotional Judgment Inventory, Champaign, IL: Institute for Personality and Assessment Testing, Inc I., 2003.

[43] A. M. Schmisseur, Beyond The Client Service Interaction: An Examination of The Emotional Labor of Change Implementers( Doctor Of Philosophy Dissertation), 2005.

[44] J. Ciarrochi, F. Deane, and S. Anderson, "Emotional intelligence moderates the relationship between stress and mental health," Personality and Individual Differences, 2002, vol. 32, pp. 197-209.

[45] J. Humphreys, B. Brunsen, and D. Davis, "Emotional structure and commitment: Implications for health care management," Journal of Health Organization and Management, vol. 19, no. 2, pp. 120-129, 2005.

[46] A. Jain and A. Sinha, "General health in organizations: Relative relevance of emotional intelligence, trust, and organizational support," International Journal of Stress Management, vol. 12, pp. 257-273, 2005.

[47] N. O. Bulik, "Emotional intelligence in the workplace: Exploring its effects on occupational stress and health outcomes in human service workers," International Journal of Occupational Medicine and Environmental Health, vol.18, pp. 167-175, 2005.
[48] M. Slaski and S. Cartwright, Emotional intelligence training and its implications for stress, health, and performance, Stress and Health, 2003, vol. 19, pp. 233-239.

[49] A. M. Grant, "Enhancing Coaching Skills and Emotional Intelligence through Training," Industrial and Commercial Training, vol. 39, no. 5, pp. 257-266, 2007.

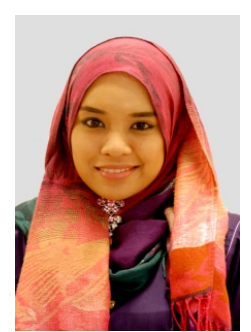

Nini Hartini Asnawi was born at Muar, Johor on 24th November 1985. She hold masters in office management system at Universiti Teknologi Mara Shah Alam, Selangor on September, 2011. Her major field of study is management.

She have been working in several places which is more towards customer service field as customer service executive at Maybank Sdn. Bhd, Salesforce Sdn. Bhd and Enche Sdn. Bhd. Currently she is being working at Universiti Teknologi Mara, Puncak Alam, Selangor as a lecturer.

She had participated in International Invention, Innovation and Design 2013 at UiTM Perlis, Malaysia for An Innovation Knowledge Transfer Model and had been awarded for Bronze Medal. 